\title{
Chronic conditions and self-perceived health among older employees in relation to indicators of labour participation and retirement over time
}

\author{
Jacqueline G.M. Jennen*, Nicole W.H. Jansen, Ludo G.P.M. van Amelsvoort, Jos J.M. Slangen \\ and IJmert Kant \\ Department of Epidemiology, School for Public Health and Primary Care (CAPHRI), Maastricht University, \\ Maastricht, The Netherlands
}

Received 15 March 2021

Accepted 14 July 2021

\begin{abstract}
.
BACKGROUND: A significant proportion of older employees leave the labour market early, amongst others via unemployment or disability benefits, implying that health might affect possibilities to extend working life.

OBJECTIVE: This study 1) examined associations between chronic conditions (subtypes) and self-perceived health (SPH), independently, and indicators of labour participation and retirement over six-year follow-up among older employees, and 2) explored the impact of differences between prevalent and incident presence of chronic condition(s) in this relation.

METHODS: Older workers (aged $>45$ years) included in the Maastricht Cohort Study were studied $(n=1,763)$. The Health and Work Performance Questionnaire assessed chronic conditions and one item from the Short Form health survey-36 assessed SPH. Cox regression analyses assessed associations between chronic conditions and SPH, independently, and retirement intentions, employment status, decreasing working hours, and changes in work over time.

RESULTS: Employees with coexistent physical-mental chronic conditions showed higher risks to lose employment and to receive a disability benefit (HR 1.85, 95\% CI 1.23-2.78; HR 8.63, 95\% CI 2.47-30.11) over time compared to healthy employees. No statistically significant associations were found between SPH and indicators of labour participation and retirement over time. Having chronic condition(s) was cross-sectionally associated with lower SPH scores and larger proportion of part-timers - compared to healthy employees.

CONCLUSIONS: Chronic condition(s) among older employees were substantially associated with indicators of labour participation and retirement over time. The role of SPH was mainly instantaneous. Findings provide valuable input for preventive measures aiming to prevent an early labour market exit of older employees.
\end{abstract}

Keywords: Objective health, subjective health, observational, ageing workers, prospective

\footnotetext{
*Address for correspondence: Jacqueline G.M. Jennen, MSc, Department of Epidemiology, School for Public Health and Primary Care (CAPHRI), Maastricht University, P.O. Box 616, 6200 MD Maastricht, The Netherlands. Tel.: +31 043 3882377; E-mail: jacqueline.jennen@maastrichtuniversity.nl.; ORCID ID: 0000-0003-4692-7840
}

\section{Introduction}

The working population is ageing due to, amongst others, increasing life expectancy. This leads to an increased need for labour participation $[1,2]$. To minimize the burden on social security and pension systems [3,4] several policy measures (such 
as increasing legal retirement age) have been implemented $[3,5,6]$, which have led to a substantial increase in the general net labour participation rate of employees among European countries, such as the Netherlands [5, 7]. Yet, amongst older employees and/or employees suffering from chronic condition(s), the percentage of employees involved in labour participation remains lower [8, 9]. As an illustration, the overall labour participation rate in Europe amongst people aged 20-64 years was 72.4 per cent in 2018 [10], whereas for older employees (aged 55-64 years) this was 57.8 per cent [10]. Additionally, the prevalence of chronic conditions is increasing. Currently, more than a quarter of the overall working population in the European Union reports having chronic condition(s) $[4,11,12]$. Among older European employees aged 45-65 years, 35.0 per cent works whilst suffering from a long-standing illness in 2018 [11].

There is no uniform definition of chronic conditions [8]. The World Health Organization (WHO) states: "chronic conditions are health problems requiring ongoing treatment for a period of years or decades', implying that chronic conditions are recurrent, long-lasting and persistent, and cannot be cured [8]. Chronic conditions have a substantial impact on labour market participation both at the macro and micro level $[8,13,14]$. At the macro level, chronic conditions contribute to substantial healthcare costs and reduced capacity of the work force since employees with chronic condition(s) leave the labour market earlier $[3,4,11,12$, 15-17]. At the micro level, chronic conditions may request adjustments in working life (such as adaptation of working hours) and coping of the individual employee [8].

Previous studies showed that chronic conditions amongst older employees are predominantly considered a decisive factor to determine whether or not to continue working or to retire (earlier) [13, 18-22]. Employees suffering from chronic condition(s) often perceive difficulties to remain involved in employment or to re-enter employment after absence [4, $8,12,23,24]$. Poor health is considered a strong predictor for employees to exit the labour market specifically via early retirement benefits, unemployment or disability benefits $[8,14,15,17,19,20$, 24-26]. Yet, these studies often assessed health as a broad concept in terms of ill or poor health [20, $27,28]$. It is of added value to distinguish between mental and physical chronic condition(s) since they affect labour participation differently [3, 16, 22].
Mental chronic condition(s) strongly affect labour participation in terms of higher absenteeism and/or presentism, and higher sickness benefits, disability benefits, and unemployment insurance benefits [3, $15,16]$. Physical chronic condition(s) are often associated with limitations in work activities, and strongly influence the retirement decision-making process. Often, physical chronic conditions oblige employees to retire early involuntary [29]. Also the combination of at least one mental and one physical chronic conditions simultaneously is frequently common due to common risk factors $[3,30]$. This combination is considered even more disabling, affecting work loss and retirement $[17,30]$. In this study, this combination is referred to as 'coexistent physical-mental chronic conditions', irrespectively of order.

In order to provide input for preventive measures aiming to prevent early labour market exit amongst older employees and to gain more insight into the potential impact of health on the possibility to extend working life, it is invaluable to study self-perceived health (SPH) in addition to chronic condition(s). $\mathrm{SPH}$ is considered an important predictor affecting the ability and willingness to extend working life amongst older employees [18, 31, 32]. Even without any diagnosed illness employees might still perceive their health as poor [32], which underlies the importance to study the impact of SPH, separately, within the same study population. Poor SPH is strongly associated with early labour market exit, more specifically with an increased risk to apply for a disability pension [20, 31, 32]. Contrary, good SPH health is considered a strong predictor to work until retirement for both older workers with and without chronic condition(s) [21].

The first goal of this study is therefore to gain more insight into the potential impact of chronic conditions (mental, physical, or coexistent physicalmental chronic conditions) and SPH, independently, on labour participation and retirement outcomes of older employees over time.

When studying this relation, it is important to also consider both willingness (intentions and motivations) and ability of older employees to extend working life. Therefore, both objective as well as subjective outcome measures will be distinguished in order to advance our understanding of labour participation and retirement amongst older employees. Chronic conditions are strongly associated with retirement intentions [19, 32, 33]. Since exit from paid employment might be a gradual process [34] and employees might make adjustments in the work 
situation in order to accommodate working whilst having chronic condition(s), a decrease in working hours should be assessed and taken into account when studying the relation between health and retirement. SPH is strongly associated with (early) labour market exit amongst older employees [31,32], therefore various labour market exit routes should ideally be explored such as disability or unemployment benefits. This study will thus assess both objective (employment status; potential exit routes; and working hours) and subjective (retirement intentions and whether changes were made in work due to health reasons) outcome measures.

Among employees with a chronic condition, the presence of (a) chronic condition(s) can be prevalent or incident, which might also affect employees' ability to continue working [35]. The second goal of this study is therefore to explore the potential role of differences between prevalent and incident presence of chronic condition(s) on the distribution of SPH and on labour participation and retirement among older employees.

To conclude, this longitudinal study aims to firstly gain more insight into the potential impact of chronic conditions (mental, physical, coexistent physical-mental chronic condition(s)) and SPH, independently, on labour participation and retirement among older employees over a six-year follow-up period. Secondly, this study aims to explore the impact of differences between prevalent and incident presence of chronic condition(s) when studying this relation. Study findings might serve as valuable input for the development of preventive measures aiming to facilitate sustainable employment for older employees with deteriorating health in terms of both chronic condition(s) and SPH.

\section{Methods}

\subsection{Study population}

This study is based on data from the ongoing Maastricht Cohort Study (MCS) [36]. At baseline measurement in May 1998, $n=12,140$ respondents from 45 companies were included [37]. Extensive self-administered questionnaires were used to collect data on multiple follow-up waves. The design of this prospective cohort is described elsewhere [37].

The 2008 wave $(n=6,082)$ was considered article baseline (T0), and two follow-up measurements 2012 ( $T=48$ months) and 2014 ( $T=72$ months) were used in this study, since items and concepts for both health and labour participation were measured consistently over these waves, resulting in a total follow-up period of six years. At $T=48$ months, $n=5,814$ questionnaires were sent out and $n=4,783$ valid questionnaires were received. At $T=72$ months, $n=3,450$ questionnaires were sent out to employees not fully retired at $T=72$ months and $n=2,945$ valid questionnaires were received (85.4\%). Employees who indicated being fully retired at $T=72$ months received a separate questionnaire $(n=1,284)$ and were not eligible for inclusion.

At T0, employees aged 45 to 59.17 years and who indicated being in current employment by an employer $(n=3,782)$ were included. Workers aged below 45 years were excluded since these were not considered older employees. Employees aged 59.17 years onwards were excluded, since they could reach the (in that time window applicable) legal retirement age of 65 years and 2 months during the follow-up Moreover, employed employees yet who also indicated being (partly) disabled, being on sabbatical - pregnancy - or parental leave, receiving (partially) disability or unemployment benefits, or being in (partially) retirement, were excluded since some were our main outcomes of interests and our study population should still be actively employed at T0 in order to study incident cases of (early) labour force exit routes over time. Additionally, selfemployed employees were excluded, due to potential substantial differences in work content and responsibility, and different entitlement to receive (disability or unemployment) benefits compared to employees employed by an employer. Employees with multiple jobs were excluded since no information available on the content of the second job. Moreover, employees performing night and/or shift work, or working irregular hours, were excluded since these outside regular working hours are divers and each affect employees' well-being and health differently [38]. This resulted in a total study population of $n=1,763$ older employees at T0. Furthermore, employees who did not complete all items required for respectively calculating chronic conditions $(n=64)$ or SPH $(n=8)$ were excluded, resulting in respectively $n=1,699$ employees for analyses regarding chronic conditions and $n=1,755$ employees for analyses regarding SPH.

\subsection{Health status of employees}

The validated Health and Work Performance Questionnaire (HPQ) was used to identify the presence 
of 34 pre-specified health conditions [39]. The 34 pre-specified conditions of the HPQ were matched with the International Classification of Primary Care-Version 2 (ICPC-2) codes of 28 pre-specified conditions listed by the Dutch National Institute of Public Health and Environment (RIVM) [40, 41]. Several health conditions on the HPQ list might be considered determinants or precursors of disease(s) such as overweight or hypertension, and were therefore not defined as chronic condition(s) according to the RIVM listing [42]. Seventeen chronic mental or physical conditions of the HPQ directly matched with the conditions listed by the RIVM. Some condition(s) Employees could indicate whether or not they have chronic condition(s) and whether they had received or currently received treatment for the(se) condition(s) [39]. Employees were labelled as having one (or more) condition(s) when marking for that condition the answers: 'Yes, I currently have this condition' and; 'I have never received a treatment', 'I have received a treatment in the past', or 'I am currently receiving treatment'. Additionally, employees could list one health condition, which was not previously listed, in an open-ended question.

\subsubsection{Healthy employees}

Employees indicating 'No, I currently do not have this condition' to all seventeen mental or physical chronic conditions and additionally did not list a mental or physical chronic condition in the openended question, were considered the reference group of healthy employees. This resulted in $n=978$ healthy employees at $\mathrm{T} 0$.

\subsubsection{Mental chronic condition(s)}

Employees indicating having at least one or more of the following mental chronic condition(s): burnout, anxiety disorder, depression, schizophrenia or other psychotic disorder, and/or bipolar disorder (including mania, hypomania), and not indicating to have (a) physical chronic condition(s), were included in the group of employees having mental chronic condition(s). This resulted in $n=62$ employees with at least one or more mental chronic condition(s) at T0.

\subsubsection{Physical chronic condition(s)}

Employees indicating having at least one or more of the following physical chronic condition(s): asthma, chronic obstructive pulmonary disease (COPD), heart disease, consequences of a stroke or cerebral infarction, liver inflammation or cirrhosis of the liver, type I diabetes, type II diabetes, chronic back / neck pain, arthritis or rheumatism, nervous system disease (including epilepsy, MS), migraine, and/or cancer, and not indicating to have (a) mental chronic condition(s), were included in the group of employees having physical chronic condition(s). This resulted in $n=551$ employees with at least one or more physical chronic condition(s) at T0.

\subsubsection{Coexistent physical-mental chronic conditions}

Employees indicating having at least one mental chronic condition(s) and at least one physical chronic condition(s) simultaneously, were included in the group of employees having coexistent physicalmental chronic conditions. This resulted in $n=108$ employees with at least one mental and at least one physical chronic condition at $\mathrm{T} 0$.

\subsection{Differences between prevalent and incident presence of chronic condition( $s$ )}

Employees were identified as either having or not having (a) chronic condition(s) at T0. Additionally, employees' health status was assessed at the subsequent follow-up measurement ( $T=48$ months). Again, seventeen chronic mental or physical conditions in the HPQ list matched directly with the conditions listed by the RIVM [41]. As such, three groups of employees were identified at $T=48$ months: employees indicating neither having (a) chronic condition(s) at T0 nor at follow-up measurement, were classified as healthy employees $(n=593)$; employees indicating not having (a) chronic condition(s) at T0 yet indicating having (a) chronic condition(s) at follow-up measurement, were classified as employees with incident chronic condition(s) $(n=180)$; and employees indicating having (a) chronic condition(s) both at T0 and at followup measurement, were classified as employees with prevalent chronic condition(s) $(n=409)$.

\subsection{Self-perceived health}

SPH was measured at $\mathrm{T} 0$ by using an item from the Dutch version of the Short Form Health Survey-36 (SF-36 item) [37, 43]. The SF-36 Health Survey is a widely used generic health status measurement [43], originally developed to examine the self-reported health status of patients with a range of chronic conditions $[43,44]$. The item asked: 'How do you rate your general health', with five answer possibilities: excellent, very good, good, moderate, or poor. In line with 
[45], the five answer possibilities were dichotomized into 'good health' (excellent, very good, good) and 'moderate/poor health' (moderate, bad). Employees with good SPH were considered the reference group.

\subsection{Indicators of labour participation and retirement}

\subsubsection{Retirement intentions}

At $\mathrm{T} 0$ and $T=48$ months and $T=72$ months, employees' retirement intentions were assessed by using a single-item 'Have you considered retiring before reaching your mandatory retirement age?'. Answer possibilities were 'no', 'yes, sometimes', and 'yes, often'. In line with other studies [46, 47], answer possibilities were dichotomized into having weak retirement intentions (no; yes, sometimes) and having strong retirement intentions (yes, often).

\subsubsection{Working hours}

At T0 and follow-up measurements, one item assessed the number of working hours per week. Response options were: $>40,36-40,26-35,16-25$, or $<16$ hours per week, which were recoded into: fulltime ( $>40$ or $36-40 \mathrm{~h}$ per week), or part-time (26-35, $16-25,<16 \mathrm{~h}$ per week) employment. Employees indicating to transit from full-time employment at T0 to part-time employment at follow-up measurement, were classified as having decreased working hours.

\subsubsection{Changes in work due to health reasons}

Employees could indicate whether they 'made changes in work due to health reasons in the past year' at T0. Answer possibilities were 'no' or 'yes'.

\subsubsection{Employment status}

At T0, all employees were in employment by an employer. At $T=48$ months and $T=72$ months, employees were again asked to provide an overview of their work status since the previous questionnaire. At $T=48$ months, employees indicating being 'in employment by an employer' or 'in self-employment (fully or partially)' were classified as being in employment. All other employees were classified as having 'lost employment' at $T=48$ months, irrespective of the underlying reason(s). At $T=72$ months, employees indicating being in 'paid work' or 'in selfemployment (fully or partially)' were classified as being in employment. All other employees were classified as having 'lost employment' at $T=72$ months, irrespective of the underlying reason(s).

\subsubsection{Labour force exit route}

At T0, all employees were employed. At follow-up measurements, employees could have lost employment. To assess the underlying reason(s) of having lost employment, the following labour force exit routes were specified at $T=48$ months and $T=72$ months: disability benefits, unemployment benefits, and retirement benefits.

\subsubsection{Disability benefits}

Employees indicating being '(partially) incapacitated for work at $T=48$ months', or employees indicating being '(partially) incapacitated for work according to the Dutch work disability act (WAO/WIA)' at $T=72$ months, were classified as receiving disability benefits.

\subsubsection{Unemployment benefits}

Employees indicating 'to receive an unemployment benefit' or who 'actively searched for a (paid) job' at $T=48$ months, or employees indicating being '(partly) involuntarily unemployed (unemployment benefit)' at $T=72$ months, were classified as receiving unemployment benefits.

\subsubsection{Retirement benefits}

Employees indicating to be in '(early or part-time) retirement' at $T=48$ months, or employees indicating 'being (partly) retired' at $T=72$ months, were classified as receiving retirement benefits.

\subsection{Confounding and contextual factors}

Based on previous research $[1,20,48]$, confounding factors from the personal/private, work, and health domain were identified. All confounding factors were measured at T0, except for respondents' educational level which was measured at May 1998.

\subsubsection{Personal/private domain}

Age, gender, educational level, and whether or not living alone, were assessed. Employees were asked to indicate their highest completed level of education - which was recoded: low (primary school, lower vocational education), medium (lower secondary school, intermediate vocational school, upper secondary school), or high (higher vocational school, university) educational level [6].

\subsubsection{Work domain}

Decision latitude and psychological job demands were measured by using the validated Dutch version 
of the Job Content Questionnaire (JCQ) [49]. All subscales from the JCQ had a four-point answer scale ranging from 'strongly disagree' to 'strongly agree'. Decision latitude was measured by the sum of two subscales: skill discretion (six items; e.g. 'My job requires a high level of skill') and decision authority (three items; e.g. 'I have a lot to say about what happens on my job'). Psychological job demands were assessed by the sum of five items (e.g. 'My job requires working very hard'). The total subscale score ranges from 24-96 for decision latitude and 12-48 for psychological job demands. Co-worker social support (four items; e.g. 'People I work with are helpful in getting the job done') and supervisor social support (four items; e.g. 'My supervisor is helpful in getting the job done') were measured with scale ranges from 4-16. Emotional demands were measured by the five questions, of which three questions originate from the Dutch Questionnaire on the Experience and Evaluation of Work (VBBA) [50, 51], one question originates from the Dutch questionnaire on Work and Health [49], and one question is self-formulated, resulting in a scale score ranging from 0 to 5 . As mentioned above, one item assessed working hours (per week). The five answer options: $>40,36-40,26-35$, $16-25$, or $<16 \mathrm{~h} /$ wk were recoded into full-time $(>40$ or 36-40 h per week), or part-time (26-35, 16-25, $<16 \mathrm{~h}$ per week) employment. Furthermore, one item from the Dutch questionnaire on Work and Health [49] assessed physically demanding work (yes/no).

\subsubsection{Health domain}

When assessing the longitudinal association between chronic condition(s) and indicators of labour participation and retirement over time, SPH was considered a confounding variable. When assessing the longitudinal association between SPH and indicators of labour participation and retirement over time, the presence of chronic condition(s) was considered a confounding variable.

\subsection{Statistical analyses}

All analyses were undertaken using SPSS Statistics IBM 22.0. $P$-values below 0.05 were considered statistically significant. At T0, demographic/private, work, and health factors, and indicators of labour participation and retirement (working hours, retirement intentions, changes in work due to health reasons), were described for employees based on chronic conditions and SPH. Differences at T0 across the groups were examined using one-way ANOVA for con- tinuous measures and $\chi 2$-test of independence for dichotomous and categorical variables. For the crosssectional analyses, no adjustments were made for potential confounding factors. Additionally, at $T=48$ months, the distribution of SPH was described for employees based on differences between prevalent and incident presence of chronic condition(s) by using one-way ANOVA for continuous measures and $\chi^{2}$-test of independence for dichotomous and categorical variables. For the longitudinal analyses, Cox regression analyses were performed to assess the relation between chronic conditions and $\mathrm{SPH}$, independently, on all indicators of labour participation and retirement: retirement intentions, employment status, labour force exit routes (disability or unemployment benefits, or (early) retirement benefits), and decreasing working hours over time. The reference group consisted of respectively healthy employees and employees with good SPH. For the longitudinal analyses, adjustments were made for potential confounding factors. In the first model, adjustments were made for age, gender, educational level, and whether or not living alone. In the second model, additional adjustments were made for physically demanding work, psychological job demands, decision latitude, emotional demands, co-worker social support, supervisor social support, and working hours. In the third model, additional adjustments were made for respectively SPH and the presence of (a) chronic condition(s). Prevalent cases for the respective indicator of labour participation and retirement at $\mathrm{T} 0$ were excluded in order to study solely incident cases at follow-up. Hazard ratios (HRs) and 95\% confidence intervals $(95 \% \mathrm{CI})$ were calculated.

\section{Results}

The baseline characteristics for employees based on chronic conditions and SPH are presented in Table 1. Statistically significant differences were observed between healthy employees and employees with respectively physical and coexistent physicalmental chronic conditions regarding demographic factors (gender and educational level). Demographic factors (age, living alone, and financial circumstances) also significantly differed amongst employees with good SPH and employees with moderate/poor SPH. As for health factors, employees with mental, physical, or coexistent physical-mental chronic conditions more often indicated moderate/poor SPH (respectively 11.5; 20.0; and 33.3\%) 
Table 1

Description of demographic/private, work-related, and health factors for healthy employees, employees with mental, physical, or coexistent physical-mental chronic conditions, and employees with good SPH or moderate/poor SPH at article baseline (2008)

\begin{tabular}{|c|c|c|c|c|c|c|c|c|}
\hline & $\begin{array}{l}\text { Healthy } \\
\text { employees } \\
(n=978)\end{array}$ & $\begin{array}{c}\text { Employees with } \\
\text { mental chronic } \\
\text { condition(s) } \\
(n=62)\end{array}$ & $\begin{array}{l}\text { Employees with } \\
\text { physical chronic } \\
\text { condition(s) } \\
(n=551)\end{array}$ & $\begin{array}{c}\text { Employees with } \\
\text { coexistent } \\
\text { physical-mental } \\
\text { chronic conditions }(n=108)\end{array}$ & $p$-value & $\begin{array}{l}\text { Good SPH } \\
(n=1,550)\end{array}$ & $\begin{array}{c}\text { Moderate/poor } \\
\text { SPH } \\
(n=205)\end{array}$ & $p$-value \\
\hline \multicolumn{9}{|l|}{ Demographic and private factors } \\
\hline Age (Years) (Mean, SD) & $52.04(3.97)$ & $52.02(4.02)$ & $52.33(4.04)$ & $52.26(3.93)$ & 0.574 & $52.02(4.00)$ & $52.99(3.79)$ & $0.001 *$ \\
\hline \multicolumn{9}{|l|}{ Gender $\quad(\mathrm{N}, \%)$} \\
\hline $\begin{array}{l}\text { Male } \\
\text { Educational level }\end{array}$ & \multicolumn{7}{|c|}{ Educational level } & 0.716 \\
\hline Low & $174(18.0)$ & $19(31.1)$ & $134(24.8)$ & $31(29.8)$ & $<0.001^{*}$ & $322(21.1)$ & $53(26.2)$ & 0.090 \\
\hline Middle & $279(28.9)$ & 15 (24.6) & $181(33.5)$ & $25(24.0)$ & & $450(29.5)$ & $65(32.2)$ & \\
\hline High & $513(53.1)$ & $27(44.3)$ & $225(41.7)$ & $48(46.2)$ & & $753(49.4)$ & 84 (41.6) & \\
\hline \multicolumn{9}{|l|}{ Living alone } \\
\hline \multirow{2}{*}{\multicolumn{9}{|c|}{ Partner retired }} \\
\hline & & & & & & & & \\
\hline Yes & $21(2.4)$ & $1(1.8)$ & $16(3.3)$ & $4(4.5)$ & 0.565 & $36(2.4)$ & $7(3.5)$ & 0.250 \\
\hline \multicolumn{9}{|l|}{ Satisfied with financial circumstances } \\
\hline Yes & $877(89.9)$ & $49(80.3)$ & $470(85.6)$ & $88(81.5)$ & $0.004 *$ & $1,374(88.9)$ & $159(77.9)$ & $<0.001 *$ \\
\hline \multicolumn{9}{|l|}{ Work-related factors } \\
\hline \multicolumn{9}{|l|}{ Physically demanding work } \\
\hline Yes $\quad(\mathrm{N}, \%)$ & $113(11.6)$ & $8(13.1)$ & $114(20.7)$ & $28(26.7)$ & $<0.001^{*}$ & $222(14.4)$ & $52(25.6)$ & $<0.001 *$ \\
\hline Psychological job demands $^{(a)} \quad$ (Mean, SD) & $31.27(5.47)$ & $31.45(6.54)$ & $32.25(5.60)$ & $33.79(5.49)$ & $<0.001^{*}$ & $31.64(5.49)$ & $32.56(6.30)$ & $0.028 *$ \\
\hline Decision latitude ${ }^{(b)}$ & $75.03(9.66)$ & $72.23(10.44)$ & $73.71(10.28)$ & $70.95(11.87)$ & $<0.001 *$ & $74.52(10.01)$ & $71.50(10.41)$ & $<0.001 *$ \\
\hline Emotional demands (c) & $.98(1.11)$ & $1.33(1.22)$ & $1.40(1.31)$ & $1.81(1.53)$ & $<0.001 *$ & $1.15(1.22)$ & $1.48(1.38)$ & $<0.001 *$ \\
\hline Co-worker social support ${ }^{(\mathrm{d})}$ & $12.02(1.35)$ & $11.93(1.67)$ & $11.96(1.41)$ & $11.95(1.79)$ & 0.822 & $12.01(1.38)$ & $11.92(1.68)$ & 0.398 \\
\hline Supervisor social support ${ }^{(\mathrm{d})}$ & $10.69(2.26)$ & $10.40(2.80)$ & $10.72(2.21)$ & $10.02(2.34)$ & $0.021 *$ & $10.71(2.23)$ & $10.12(2.59)$ & $<0.001 *$ \\
\hline \multicolumn{9}{|l|}{ Health factors } \\
\hline $\mathrm{SPH} \quad(\mathrm{N}, \%)$ & $930(95.2)$ & $54(88.5)$ & $439(80.0)$ & $72(66.7)$ & $<0.001^{*}$ & I & I & I \\
\hline Good $^{1}$ & $930(95.2)$ & $54(88.5)$ & $439(80.0)$ & $72(66.7)$ & $<0.001 *$ & I & l & I \\
\hline Moderate/poor ${ }^{2}$ & $47(4.8)$ & $7(11.5)$ & $110(20.0)$ & $36(33.3)$ & & l & l & l \\
\hline SPH $(0-100) \quad$ (Mean, SD) & $59.72(17.86)$ & $52.87(16.52)$ & $50.50(18.34)$ & $42.36(13.87)$ & $<0.001^{*}$ & I & l & l \\
\hline \multicolumn{9}{|l|}{ Depressive complaints $^{(\mathrm{e})}$} \\
\hline Number of conditions $\quad(\mathrm{N}, \%)$ & $2.39(2.77)$ & $4.90(4.05)$ & $3.05(3.08)$ & $5.56(3.61)$ & $<0.001 *$ & $2.56(2.85)$ & $5.44(3.77)$ & $<0.001 *$ \\
\hline 0 & $978(100)$ & $0(0)$ & $0(0)$ & $0(0)$ & $<0.001 *$ & $930(64.6)$ & $47(27.5)$ & $<0.001 *$ \\
\hline 1 & $0(0)$ & $38(74.5)$ & $360(72.4)$ & $0(0)$ & & $342(23.8)$ & $54(31.6)$ & \\
\hline$>=2$ & $0(0)$ & $13(25.5)$ & $137(27.6)$ & $88(100.0)$ & & $167(11.6)$ & $70(40.9)$ & \\
\hline
\end{tabular}

(a) = scale range = 12-48; (b) = scale range =24-96; (c) = scale range =0-5; (d) = scale range =4-16; (e) = scale range =0-21 using HADS; 1 : Good SPH, 2: moderate/poor SPH; (e) = scale range $=0-21$. 
Table 2

Description of indicators of labour participation and retirement for healthy employees, employees with mental, physical, or coexistent physical-mental chronic conditions, at article baseline (2008)

\begin{tabular}{|c|c|c|c|c|c|c|c|c|}
\hline & $\begin{array}{c}\text { Healthy } \\
\text { employees } \\
(n=978)\end{array}$ & $\begin{array}{c}\text { Employees } \\
\text { with mental } \\
\text { chronic } \\
\text { condition(s) } \\
(n=62) \\
\end{array}$ & $\begin{array}{c}\text { Employees } \\
\text { with physical } \\
\text { chronic } \\
\text { condition(s) } \\
(n=551) \\
\end{array}$ & $\begin{array}{l}\text { Employees with } \\
\text { coexistent } \\
\text { physical-mental } \\
\text { chronic conditions } \\
(n=108)\end{array}$ & $p$-value & $\begin{array}{c}\text { Good } \\
\text { SPH } \\
(n=1,550)\end{array}$ & $\begin{array}{c}\text { Moderate/poor } \\
\text { SPH } \\
(n=205)\end{array}$ & $p$-value \\
\hline \multicolumn{9}{|c|}{ Retirement intentions $\quad(\mathrm{N}, \%)$} \\
\hline Strong & $151(15.5)$ & $18(29.0)$ & $102(18.6)$ & $31(28.7)$ & \multirow{3}{*}{$<0.001^{*}$} & $240(15.6)$ & $71(34.8)$ & \multirow{3}{*}{$<0.001^{*}$} \\
\hline Weak & $823(84.5)$ & $44(71.0)$ & $445(81.4)$ & $77(71.3)$ & & $1,302(84.4)$ & $133(65.2)$ & \\
\hline \multicolumn{7}{|c|}{ Working hours } & & \\
\hline Full-time & $768(79.1)$ & $47(77.0)$ & $401(73.3)$ & $71(67.0)$ & \multirow[t]{2}{*}{$0.007^{*}$} & $1,167(76.0)$ & $156(76.5)$ & \multirow[t]{2}{*}{0.877} \\
\hline Part-time & $203(20.9)$ & $14(23.0)$ & $146(26.7)$ & $35(33.0)$ & & $369(24.0)$ & $48(23.5)$ & \\
\hline
\end{tabular}

compared to healthy employees (4.8\%). Additionally, amongst employees with moderate/poor SPH, 40.9 per cent indicated having two or more chronic condition(s), which was substantially higher compared to employees with good SPH (11.6 per cent).

\subsection{Cross-sectional associations between chronic conditions and SPH, independently, and indicators of labour participation and retirement}

\subsubsection{Retirement intentions}

The indicators of labour participation and retirement at $\mathrm{T} 0$ for employees, split for chronic conditions and $\mathrm{SPH}$, are presented in Table 2. With regards to chronic conditions, amongst employees indicating mental, physical, or coexistent physical-mental chronic condition(s), respectively $29.0 ; 18.6$; and 28.7 per cent indicated strong retirement intentions whereas amongst healthy employees 15.5 per cent indicated strong retirement intentions $(p<0.001)$. With regards to SPH, amongst employees indicating moderate/poor SPH, 34.8 per cent indicated strong retirement intentions whereas among employees indicating good SPH, 15.6 per cent indicated strong retirement intentions $(p<0.001)$.

Furthermore, cross-sectional associations between SPH and indicators of labour participation and retirement within the four distinguished groups of employees based on chronic conditions, are presented in Table 3. Amongst healthy employees, in the group with strong retirement intentions 90.1 per cent of the employees perceived good SPH, while this was 96.1 per cent in the group with weak retirement intentions at T0 $(p<0.001)$. Amongst employees with physical chronic condition(s), in the group with strong retirement intentions 37.3 per cent of the employees perceived moderate/poor SPH, while this was 16.0 per cent in the group with weak retirement intentions $(p<0.001)$. Amongst employees with mental and coexistent physical-mental chronic condition(s), no statistically significant associations were found between SPH and retirement intentions (respectively $p=0.954$ and $p=0.229$ ) (Table 3).

\subsubsection{Working hours}

With regards to chronic conditions, amongst employees indicating mental, physical or coexistent physical-mental chronic condition(s), respectively 23.0; 26.7; and 33.0 per cent indicated working parttime, whereas amongst healthy employees, 20.9 per cent indicated working part-time $(p=0.007)$ at T0. With regards to SPH, no statistically significant association was found between SPH and working hours (Table 2).

Within the four distinguished groups based on chronic conditions, results did not show statistically significant associations between SPH and working hours (Table 3 ).

\subsubsection{Change in work due to health reasons in the past year}

Within the four distinguished groups based on chronic conditions, amongst employees with mental, physical, and coexistent physical-mental chronic conditions, no statistically significant association were found between SPH and changes in work due to health reasons (Table 3 ). Results showed that amongst healthy employees, in the group of employees who made changes in work due to health reasons, 26.9 per cent of the employees perceived poor/moderate $\mathrm{SPH}$, while this was 4.2 per cent in the group of employees who did not make changes in work due to health reasons at T0 $(p<0.001)$. 
Table 3

Cross-sectional associations between SPH and indicators of labour participation and retirement for healthy employees, employees with mental or physical chronic condition(s), or coexistent physical-mental chronic conditions at article baseline (2008)

\begin{tabular}{|c|c|c|c|c|c|c|c|c|c|}
\hline & \multicolumn{3}{|c|}{ Retirement intentions } & \multicolumn{3}{|c|}{ Working hours } & \multicolumn{3}{|c|}{$\begin{array}{l}\text { Change in work due to health } \\
\text { reasons in the past year }\end{array}$} \\
\hline & Strong & Weak & & Full-time & Part-time & & Yes & No & \\
\hline & Mean, SD & Mean, SD & $p$-value & Mean, $S D$ & Mean, SD & $p$-value & Mean, SD & Mean, $S D$ & p-value \\
\hline \multicolumn{10}{|c|}{ Study population $(n=1,763)$} \\
\hline \multicolumn{10}{|l|}{ SPH } \\
\hline Good & $77.2 \%$ & $90.7 \%$ & $<0.001^{*}$ & $88.2 \%$ & $88.5 \%$ & 0.877 & $70.1 \%$ & $89.2 \%$ & $<0.001^{*}$ \\
\hline Moderate/poor & $22.8 \%$ & $9.3 \%$ & & $11.8 \%$ & $11.5 \%$ & & $29.9 \%$ & $10.8 \%$ & \\
\hline \multicolumn{10}{|c|}{ Healthy employees $(n=978)$} \\
\hline Good & $90.1 \%$ & $96.1 \%$ & $<0.001^{*}$ & $94.8 \%$ & $97.0 \%$ & 0.178 & $73.1 \%$ & $95.8 \%$ & $<0.001^{*}$ \\
\hline Moderate/poor & $9.9 \%$ & $3.9 \%$ & & $5.2 \%$ & $3.0 \%$ & & $26.9 \%$ & $4.2 \%$ & \\
\hline \multicolumn{10}{|c|}{$\begin{array}{l}\text { Employees with mental chronic } \\
\text { conditions }(n=62)\end{array}$} \\
\hline Good & $88.9 \%$ & $88.4 \%$ & 0.954 & $89.4 \%$ & $84.6 \%$ & 0.637 & $75.0 \%$ & $89.5 \%$ & 0.380 \\
\hline Moderate/poor & $11.1 \%$ & $11.6 \%$ & & $10.6 \%$ & $15.4 \%$ & & $25.0 \%$ & $10.5 \%$ & \\
\hline \multicolumn{10}{|c|}{$\begin{array}{l}\text { Employees with physical } \\
\text { chronic condition(s) }(n=551)\end{array}$} \\
\hline \multicolumn{10}{|c|}{ SPH } \\
\hline Good & $62.7 \%$ & $84.0 \%$ & $<0.001^{*}$ & $80.3 \%$ & $78.6 \%$ & 0.675 & $71.1 \%$ & $80.6 \%$ & 0.159 \\
\hline Moderate/poor & $37.3 \%$ & $16.0 \%$ & & $19.8 \%$ & $21.4 \%$ & & $28.9 \%$ & $19.4 \%$ & \\
\hline \multicolumn{10}{|c|}{$\begin{array}{l}\text { Employees with coexistent } \\
\text { physical-mental chronic } \\
\text { conditions }(n=108)\end{array}$} \\
\hline \multicolumn{10}{|l|}{ SPH } \\
\hline Good & $58.1 \%$ & $70.1 \%$ & 0.229 & $62.0 \%$ & $74.3 \%$ & 0.208 & $50.0 \%$ & $68.8 \%$ & 0.165 \\
\hline Moderate/poor health & $41.9 \%$ & $29.9 \%$ & & $38.0 \%$ & $25.7 \%$ & & $50.0 \%$ & $31.2 \%$ & \\
\hline
\end{tabular}

\subsection{Longitudinal associations between chronic conditions and SPH, independently, and indicators of labour participation and retirement}

\subsubsection{Retirement intentions}

Over six-year follow-up period, no statistical significant associations were found between chronic conditions and retirement intentions (Table 4.1.). Also, no statistical significant associations were found between SPH and retirement intentions over time (Table 4.2.).

\subsubsection{Working hours}

Employees with coexistent physical-mental chronic conditions had a substantially higher risk for decreasing working hours (HR 2.19, 95\% CI 1.18-4.08) over time compared to healthy employees (Table 4.1.). No statistical significant associations were found between SPH and decreasing working hours over time (Table 4.2.).

\subsubsection{Employment status}

Employees with coexistent physical-mental chronic conditions had a substantial higher risk to lose employment (HR 1.85, 95\% CI 1.23-2.78) over time compared to healthy employees (Table 4.1.). No statistical significant associations were found between SPH and losing employment over time (Table 4.2.).

\subsubsection{Labour force exit route \\ 3.2.5. Disability benefits}

Employees with physical and coexistent physicalmental chronic condition(s) had significant higher risks to receive disability benefits over time (respectively HR 4.65, 95\% CI 1.60-13.50; and HR 8.63, 95\% CI 2.47-30.11) compared to healthy employees (Table 4.1.). Fully adjusted models showed no statistical significant associations between $\mathrm{SPH}$ and receiving disability benefits over time (Table 4.2.). However, the second model which was solely adjusted for factors from the personal/private and work domain, showed that employees with moderate/poor SPH had a significant higher risk to receive disability benefits over time compared to employees with good SPH (HR 3.58, 95\% CI 1.55-8.25).

\subsubsection{Unemployment benefits}

No statistical significant associations were found between chronic conditions and receiving unemployment benefits over time (Table 4.1.). Additionally, 
Table 4.1

Longitudinal associations between mental $(n=62)$, physical $(n=551)$, coexistent physical-mental chronic conditions $(n=108)$ - compared to healthy employees $(n=978)$ - on losing employment, decreasing working hours, receiving disability benefits, receiving unemployment benefits, receiving retirement benefits, and having strong retirement intentions over 6-year follow-up (2008-2014)

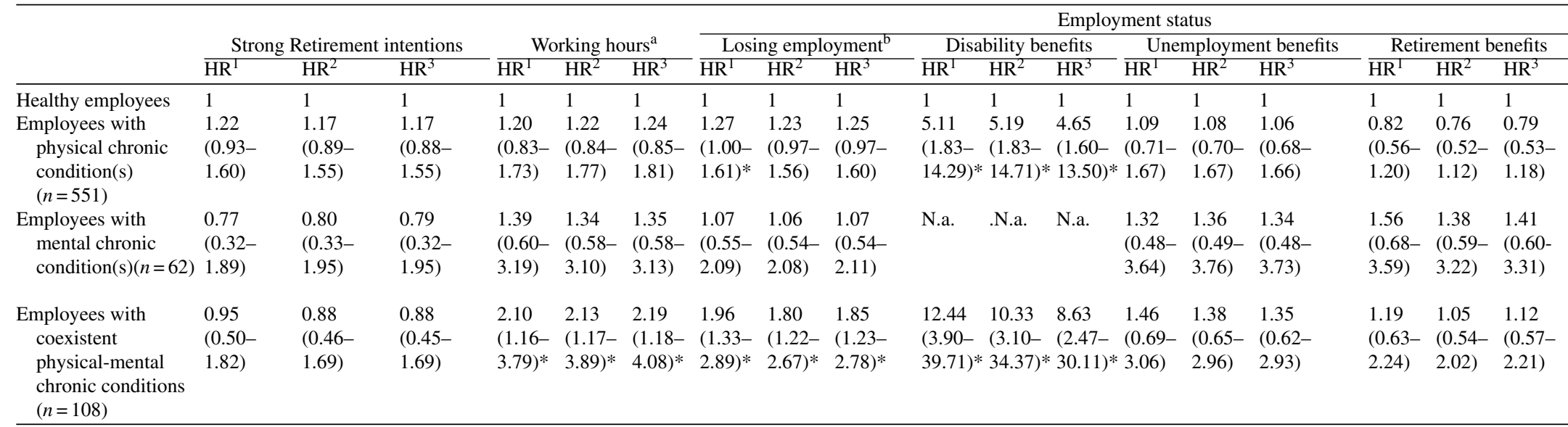

${ }^{\mathrm{a}}=$ transitionfrom full-time to part-time employment, ${ }^{\mathrm{b}}=$ not participating in employment. $1=$ adjusted for factors from the personal/private domain $($ age, gender, educational level, whether or not living alone), 2 = additionally adjusted for factors from the work domain (physically demanding work, psychological job demands, decision latitude, emotional demands, social support colleagues, social support supervisor, and working hours), 3 = additionally adjusted for SPH.N.a. could not be assessed due to insufficient cases. 


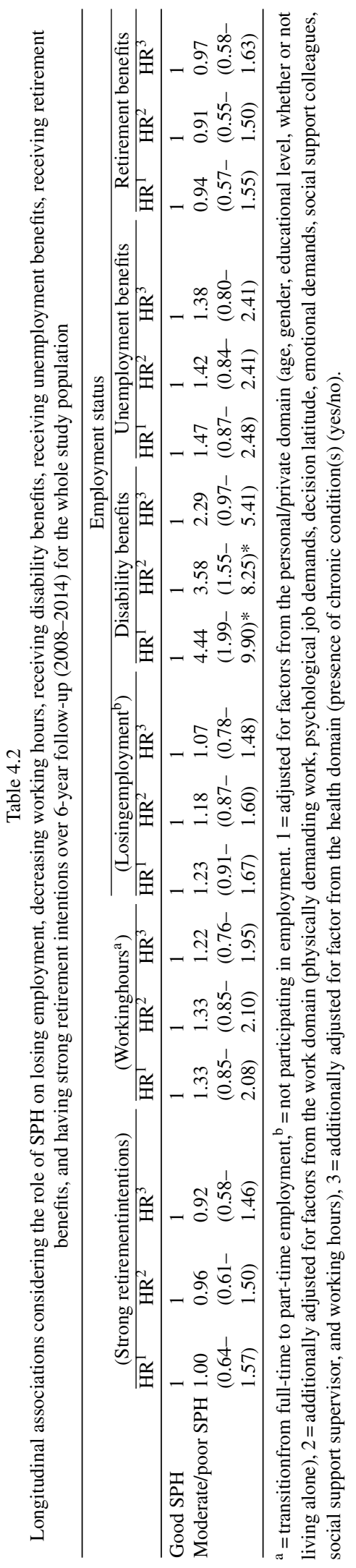

no statistical significant associations were found between SPH and receiving unemployment benefits over time (Table 4.2.).

\subsubsection{Retirement benefits}

No statistical significant associations were found between chronic conditions receiving and (early) retirement benefits over time (Table 4.1.). Also, no statistical significant associations were found between SPH and receiving unemployment benefits over time (Table 4.2.).

Exploring the role of differences between prevalent and incident presence of chronic condition(s) on SPH and indicators of labour participation and retirement among older employees: cross-sectional associations at $T=48$ months.

\subsection{Self-perceived health}

Results in Table 5 show that the highest proportion of employees indicating moderate/poor SPH was amongst employees with incident and prevalent chronic condition(s) (respectively 18.4 and $34.8 \%$ ) at $T=48$ months. Contrary, amongst healthy employees 4.0 per cent indicated moderate/poor SPH $(p<0.001)$.

\subsection{Labour participation and retirement outcomes}

\subsubsection{Retirement intentions}

No statistical significant associations were found between differences between prevalent and incident presence of chronic condition(s) and retirement intentions (Table 5).

\subsubsection{Working hours}

Results showed that the highest proportion of employees indicating working part-time was amongst employees with incident and prevalent chronic condition(s) (respectively 32.1 and $38.0 \%$ ) at $T=48$ months. Amongst healthy employees, 24.4 per cent indicated working part-time $(p<0.001)$.

\subsubsection{Changes made in work due to health reasons in the past year}

Results showed that amongst employees with incident and prevalent chronic condition(s) respectively 5.5 and 8.1 per cent indicated to have made changes in work due to health reasons in the past year. This percentage was substantially lower amongst healthy employees $(1.1 \%)(p<0.001)$. 
Table 5

Exploring the role of prevalent and incident presence of chronic condition(s): cross-sectional associations with demographic, health, and indicators of labour participation and retirement at wave 2012

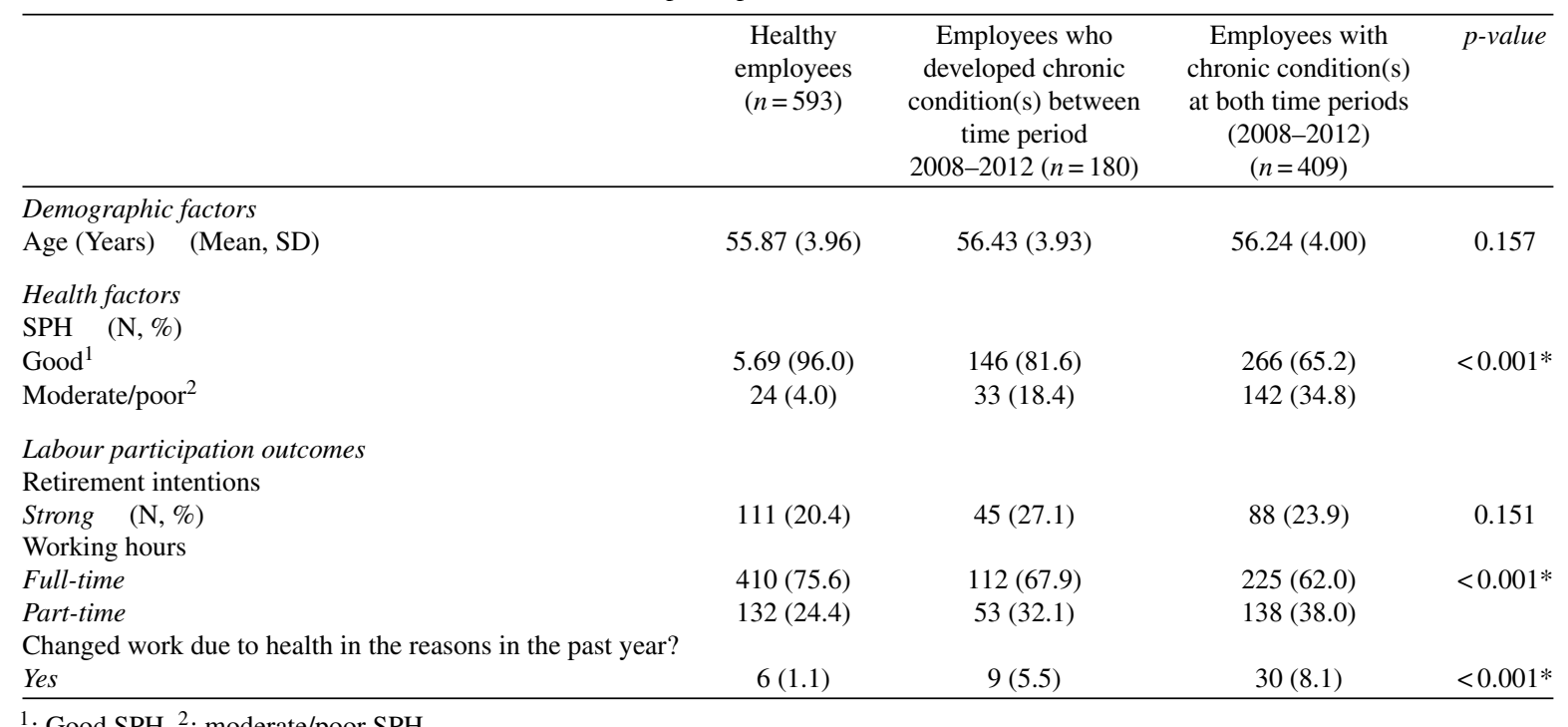

${ }^{1}$ : Good SPH, ${ }^{2}$ : moderate/poor SPH.

\section{Discussion}

This study aimed 1) to examine associations between chronic conditions (mental, physical, or coexistent physical-mental chronic condition(s)) $\mathrm{SPH}$, independently, and labour participation and retirement among older employees over a sixyear time period, and 2) to explore the potential role of prevalent and incident presence of chronic condition(s) on SPH and labour participation and retirement among older employees. In sum, study findings showed that coexistent physical-mental chronic conditions were significantly associated with strong retirement intentions and part-time employment compared to healthy employees at $\mathrm{T} 0$. Longitudinal analyses showed that employees with coexistent physical-mental chronic conditions had substantial and significant higher risks for decreasing working hours, losing employment, and receiving disability benefits over time compared to healthy employees. SPH was substantially and significantly associated with strong retirement intentions at T0. However, no significant associations were found between SPH and indicators of labour participation and retirement over time, suggesting a more instantaneous effect of SPH on indicators of labour participation and retirement. As for differences between prevalent and incident presence of chronic condition(s), descriptive findings show that the proportion of employees indicating moderate/poor SPH and working part-time was substantially higher amongst employees with respectively incident and prevalent chronic condition(s) compared to healthy employees.

In line with previous research [18, 32, 52], cross-sectional results showed that the proportion of employees with strong retirement intentions was higher amongst employees with mental and coexistent physical-mental chronic condition(s) compared to healthy employees. Additionally, the proportion of employees working part-time was higher amongst employees with physical and coexistent physicalmental chronic condition(s) compared to healthy employees. With regards to SPH, cross-sectional results showed that the proportion of employees indicating strong retirement intentions was higher amongst employees who indicated moderate/poor SPH compare to those who indicated good SPH. Yet, no significant associations were found between SPH and working hours at T0. When assessing the associations between SPH and indicators of labour participation and retirement within the four distinguished groups based on chronic condition(s) at T0, results showed that amongst healthy employees and employees with physical chronic condition(s) in the groups with strong retirement intentions, the proportion of employees indicating moderate/poor SPH was substantially higher compared to those with weak retirement intentions. Additionally, amongst healthy employees, in the group who made changes in work 
due to health reasons, the proportion of employees indicating moderate/poor SPH was substantially higher compared to those who did not made changes in work, at T0.

Longitudinal results showed that employees with coexistent physical-mental chronic conditions had substantial and significant higher risks for decreasing working hours, losing employment, and receiving disability benefits over time compared to healthy employees. Additionally, employees with physical chronic condition(s) had a substantial and significant higher risk to receive disability benefits over time compared to healthy employees, which is in line with research showing associations between chronic conditions in general and the risk to exit employment through disability and unemployment benefits $[9,14$, $19,20,24,26]$. Nearly all observed statistical significant associations over time were found amongst the group of employees with coexistent physical-mental chronic conditions. Perhaps the presence of two or more chronic conditions simultaneously within an individual may substantially increase the risk to exit paid employment [17, 22]. Study findings did not show significant associations between chronic conditions and strong retirement intentions over time. Perhaps selection processes and/or coping skills contributed to these findings. At T0, solely employees who were actively involved in labour participation were included. Perhaps the unhealthiest employees were already excluded (selective participation). Moreover, employees experiencing significant limitations due to chronic condition(s) might have already left the labour market. Employees who remained included in this study were perhaps better able to cope with chronic condition(s) whilst being in employment. With regards to SPH, these study findings did not show statistical significant associations between SPH and indicators of labour participation and retirement over time. This was contrary to our expectations, since previous research $[18,21,31$, 32] demonstrated substantial longitudinal associations. Perhaps, the lack of significant associations between SPH and indicators of labour participation and retirements over time can at least partially be explained by the numbers of employees included in the reference group $(n=1,550$ employees with good $\mathrm{SPH}$ ) and comparison group ( $n=205$ employees with poor/moderate SPH). Due to the relatively low numbers of workers included in the reference group, and exclusion of prevalent cases of the respective outcomes, the statistical power to test these specific associations could be too low, as only few cases were for these analyses over time. Also, the time period between article baseline and the first follow-up measurement was four years: perhaps this time window was too broad to observe effects over time.

As for differences between prevalent and incident presence of chronic condition(s), descriptive findings showed that the proportion of employees indicating moderate/poor SPH, working part-time and made changes in work due to health reasons, was substantially and statistically significantly higher amongst employees with incident and prevalent chronic condition(s) compared to healthy employees. Yet, these study findings did not solely find differences between employees with incident/prevalent chronic condition(s) compared to healthy employees, also substantial differences between having incident or prevalent chronic condition(s) were found. As for SPH, the proportion of employees indicating poor/moderate SPH was almost twice as big amongst employees with prevalent chronic condition(s) compared to employees with incident chronic condition(s). These findings are supported by previous studies stating that illness duration affects patients' self-rated health: the longer patients were ill, the lower their perceived health score was [33]. Moreover, these study findings showed that the proportion of employees with incident or prevalent chronic condition(s) were more likely to work part-time, compared to healthy employees. Perhaps employees with (a) chronic condition(s) reduced their working hours in order to remain in involved in (paid) employment $[4,12,33]$.

\subsection{Strengths and limitations}

When interpreting the study findings several strengths and limitations of the study should be considered. The multitude of exposure and outcome measures studied is a major advantage. By assessing both SPH and different subtypes of chronic condition(s), independently, in relation to objective and subjective outcome measures of labour participation and retirement, this study provides a more comprehensive insight into (health) factors which might affect indicators of labour participation and retirement of older employees. Within this study we were able to distinguish between mental, physical, and coexistent physical-mental chronic condition(s). For further studies it might be of additional value to take into account comorbidity when having data available of the primary condition of interest and other 
existing chronic condition(s) amongst employees suffering from comorbidity, in order to understand the impact of health on labour participation and retirement amongst older employees further. Moreover, this study defined groups of mental, physical, and coexistent physical-mental chronic condition(s) based on valid measurements. However, the severity and impact of a particular type of chronic condition might still differentially affect an employees' ability to work $[4,14]$. These study findings are thus readily generalizable to employees with chronic conditions in general, or specified to being mental and/or physical, yet not towards a specific type of chronic condition since the impact on labour participation and retirement might vary. As for SPH, the association between SPH and indicators of labour participation and retirement was studied by using one item with five answer possibilities. In line with previous research [45], these five answer possibilities were dichotomized into good SPH and moderate/poor SPH which created contrast between the two studied categories of good SPH and moderate/poor SPH in this study. For further research, it may be valuable to study SPH on a continuous scale or as a categorical variable, when numbers included within the categories are sufficient in order to assess the transition from one category of SPH to another. This might further advance the understanding of SPH on labour participation and retirement. Within this study, the effect of chronic condition(s) and SPH, separately, was studied on multiple outcome measures of labour participation and retirement. Study findings have demonstrated associations firstly, however, it should be acknowledged that these outcome measures were studied parallel, and that we cannot excluded independence of these outcome measures. Therefore, further research should secondly assess the independence of these outcome measures, thus to assess potential coherence between the outcome measures of labour participation and retirement.

Another advantage was the relatively long followup period of six years of this prospective cohort study, which enabled us to distinguished cause and effect over time. Yet, it should be noted that within this six-year follow-up period three measurements had taken place: article baseline measurement (T0), and follow-up measurements 2012 and 2014 ( $T=48$ months and $T=72$ months). Perhaps, the time inbetween measurements may sometimes be rather long in order to detect a change in outcome measures. The time in-between measurements, might also affected the observed results for differences between prevalent and incident presence of chronic condition(s) and might led to an underestimation of the observed findings, since the time window used to define incidence and prevalence of chronic condition(s) was four years [53]. Perhaps, employees with incident chronic condition(s) might have already developed (a) chronic condition(s) at the beginning of the four-year time window, making it debatable whether the condition can still be classified as being incident. These employees might already have developed coping skills to cope with this chronic condition whilst being in employment or have already made some work adjustments during this time period [8]. Those who were not able to cope the chronic condition(s) might have already left the labour market before follow-up measurement. The associations found between incident chronic conditions and outcomes of labour participation and retirement and SPH might thus underestimate the strength of the real association.

These study findings provide substantial insights for a preventive approach, since this study approaches health both in terms of chronic condition(s) and $\mathrm{SPH}$, independently, within the same study sample (total study population of $n=1,763$ at T0). Both chronic condition(s) as SPH should be considered important health-related factors affecting labour participation. Preventive measures can therefore relate to both chronic condition(s) and SPH, providing input to develop and tailor preventive measures specifically for older employees in order to extend working life. Furthermore, chronic condition(s) and SPH were studied consisting of respectively $n=1,699$ and $n=1,755$ employees for analyses studying chronic conditions and SPH, enabling us to disentangle cause and effect over time. The number of employees included within these groups was sufficient, however, the number of employees included in the group of employees with mental chronic condition(s) $(n=62)$ was too low to study incident cases for receiving disability benefits over six-year follow-up period. The relatively low number of employees with mental chronic condition(s), might also be explained by the fact that employees might already have left the labour market earlier, due to the substantial impact of mental chronic condition(s) on (paid) employment, resulting in too low number of employees with mental chronic condition(s) included in this study. Moreover, the low number of employees included in this group moreover made it difficult to compare groups, 
such as healthy employees vs. employees with mental chronic condition(s), and to draw valid conclusions. Additionally, for the longitudinal analyses regarding chronic condition(s) in relation to labour participation and retirement, healthy employees were considered the reference group. As for health status, according to this study's definition of having or not having chronic condition(s), employees in the reference group may still suffer from several health conditions, which can be considered as determinants of disease(s) such as overweight, obesity, or hypertension [42]. Thus, since older employees in the reference group could still suffer from various health conditions, no artificial contrast was created which might increase this study's external validity.

No adjustments for potential confounding factors were made for the cross-sectional analyses in this study, since the purpose of these analyses was solely descriptive. In the longitudinal analyses, adjustments were made for important confounding factors based on previous research [1, 20, 48]. As mentioned previously, various work-related factors (such as physically demanding work) could substantially affect health and vice-versa [4, 6]. Moreover, the prevalence of chronic conditions is higher amongst lower educated workers, and may consequently increase the risk to exit paid employment [22]. By adjusting for these confounding factors, potential bias may be avoided. However, we still cannot exclude (potential) residual confounding. Perhaps, various unidentified work-related confounding variables might affect the studied relation. Further research might explore more-in depth other potential undefined confounding factors when studying this relation, such as the severity of a specific type of chronic condition, or other work-related factors. Also, stratification for gender was not possible in this study due to low numbers of women included in the strata. If numbers would be sufficient, further research could also stratify for educational level or gender to assess potential differences in the observed effect over time.

Further, this study assessed a decrease in working hours, by assessing a transition from full-time to parttime employment over time. However, a decrease of working hours may also be a gradual process instead of a full instant transition from fulltime to parttime employment [34]. Therefore, future research could also explore a decrease in working hours as an absolute number of working hours, instead of a transition from full-time to part-time employment. Hereby, a decrease in working hours is then independently from employees' amount of working hours at baseline.

\subsection{Conclusion}

This study indicates substantial and statistical significant cross-sectional associations between chronic conditions and SPH, independently, and indicators of labour participation and retirement such as strong retirement intentions and working hours. As for chronic condition(s), study findings showed that employees with coexistent physical-mental chronic conditions had substantial and significant higher risks for decreasing working hours, losing employment, and receiving disability benefits over time compared to healthy employees. However, despite finding strong cross-sectional associations between SPH and indicators of labour participation and retirement, this study found no significant associations for SPH over time. Study findings suggests a rather instantaneous effect of SPH on labour participation and retirement. As for differences between prevalent and incident presence of chronic condition(s), findings show substantial difference in self-rated SPH, which was rated lowest amongst employees with prevalent chronic condition(s).

These findings include both chronic condition (s) and SPH within the same research sample and indicate that a potential (early) labor market exit as a result of declining health is not only affected by the presence of one or more chronic condition (s). In addition, SPH should also be considered when developing preventive measures to increase the (sustainable) labour participation of older workers to reach the statutory retirement age and to prevent early labour market exit. On the one hand, preventive measures should aim to reduce the emotional need for work of employees with chronic mental illness (s), or physical work demands for employees with chronic physical illness (es). On the other hand, preventive measures should also focus on SPH. However, SPH is strongly related to employees' perception of their ability to extend working life, and therefore requires a more individual approach and may require approximating other health and social variables to promote the active participation of older workers. Furthermore, future research should aim to additionally assess the role of differences between prevalent and incident presence of chronic condition(s) over time, since these study findings were solely explorative yet still showing 
strong and substantial cross-sectional associations between SPH and differences between prevalent and incident presence of chronic condition(s).

\section{Acknowledgments}

The authors thank Linda van Delden for her support in the data analysis.

\section{Author contributions}

Providing accessibility to data and data management were performed by J.J.M. Slangen. The first draft of the manuscript was written by J.G.M. Jennen, and all authors commented on previous versions of the manuscript. All authors read and approved the version to be published. All authors agreed to be accountable for all aspects of the work in ensuring that questions related to the accuracy or integrity of any part of the work are appropriately investigated and resolved.

\section{Conflict of interest}

The authors declare that they have no conflict of interest.

\section{Ethical approval}

All procedures performed in studies involving human participants were in accordance with the ethical standards of the institutional and/or national research committee and with the 1964 Helsinki Declaration and its later amendments or comparable ethical standards. The Medical Research and Ethics Committee of the Maastricht University Medical Centre approved the protocol for the Maastricht Cohort Study (MEC 08-4-032).

\section{Funding}

This study was financially supported by the Province of Limburg, The Netherlands, through the 4Limburg program, (grant number 2017/50486) and by School CAPHRI (School for Public Health and Primary Care), Maastricht University, Maastricht, the Netherlands.

\section{References}

[1] Nilsson K. Conceptualisation of ageing in relation to factors of importance for extending working life-a review. Scand J Public Healt. 2016;44(5):490-505.

[2] Boot CR, Scharn M, van der Beek AJ, Andersen LL, Elbers $\mathrm{C}$, Lindeboom M. Effects of early retirement policy changes on working until retirement: Natural experiment. Int J Environ Res Pu. 2019;16(20):3895.

[3] OECD/European Union. Health at a Glance: Europe 2018: State of Health in the EU Cycle. OECD Publishing, Paris/European Union, Brussels; 2018.

[4] Eurofound. Working conditions and workers' health. Publications Office of the European Union, Luxembourg; 2019.

[5] Eurofound. Sixth European Working Conditions Survey Overview report (2017 update). Publications Office of the European Union, Luxembourg; 2017.

[6] Hoofs H, Jansen NWH, Jansen MWJ, Kant IJ. Monitoring of need for recovery and prolonged fatigue within the working population: Evaluation of reliability and agreement over time. Work. 2017;58(3):399-412.

[7] Hengel KM, Riumallo-Herl C, Schram JL, Nieboer D, van der Beek AJ, Burdorf A. Effects of changes in early retirement policies on labor force participation: the differential effects for vulnerable groups. Scan J Work Env Hea. 2021;47(3):224.

[8] Eurofound. Employment opportunities for people with chronic diseases. Publications Office of the European Union, Luxembourg; 2014.

[9] Rijken M, Spreeuwenberg P, Schippers J, Groenewegen PP. The importance of illness duration, age at diagnosis and the year of diagnosis for labour participation chances of people with chronic illness: results of a nationwide panel-study in the Netherlands. BMC Public Health. 2013;13(1):803.

[10] Eurostat. Employment rate by age 2020 [internet]. Available from: https://ec.europa.eu/eurostat/databrowser/ product/view/LFSI_EMP_A. [Accessed 25-08-2020].

[11] Eurostat. People having a long-standing illness or health problem, by sex, age and labour status 2020 [internet]. Available from: http://ec.europa.eu/eurostat/web/productsdatasets/-/hlth_silc_04. [Accessed 25-08-2020].

[12] Eurofound. How to respond to chronic health problems in the workplace? Publications Office of the European Union, Luxembourg; 2019.

[13] Fleischmann M, Carr E, Stansfeld SA, Xue B, Head J. Can favourable psychosocial working conditions in midlife moderate the risk of work exit for chronically ill workers? A 20-year follow-up of the Whitehall II study. Occup Environ Med. 2018;75(3):183-90.

[14] Holman D. Chronic conditions as predictors of later life disability employment exit: a gendered analysis. Occup Environ Med. 2019;76(7):441-7.

[15] OECD/European Union. Health at a Glance: Europe 2016: State of Health in the EU Cycle. OECD Publishing, Paris/European Union, Brussels; 2016.

[16] Bernfort L, Persson J, Linderoth C, Ekberg K. Supervisor ratings of productivity loss associated with presenteeism and sick leave due to musculoskeletal disorders and common mental disorders in Sweden. Work. 2021. (Preprint), 1-10.

[17] Harber-Aschan L, Chen WH, McAllister A, Koitzsch Jensen N, Thielen K, Andersen et al. The impact of longstanding illness and common mental disorder on competing employment exits routes in older working age: A longitudinal data-linkage study in Sweden. PloS One. 2020;15(2):e0229221. 
[18] Nilsson K, Hydbom AR, Rylander L. How are self-rated health and diagnosed disease related to early or deferred retirement? A cross-sectional study of employees aged 5564. BMC Public Health. 2016;16(1):886.

[19] Ôzdemir E, Fuchs TWM, Ilinca S, Lelkes O, Rodrigues R, Zolyomi E. Employment of older workers: report. Verlag: European Union; 2016.

[20] Reeuwijk KG, van Klaveren D, van Rijn RM, Burdorf A, Robroek SJ. The influence of poor health on competing exit routes from paid employment among older workers in 11 European countries. Scan J Work Env Hea. 2017;24-33.

[21] Sewdas R, van der Beek AJ, de Wind A, van der Zwaan LG, Boot CR. Determinants of working until retirement compared to a transition to early retirement among older workers with and without chronic diseases: results from a Dutch prospective cohort study. Scan J Public Healt. 2018;46(3):400-8.

[22] Hengel KO, Robroek SJ, Eekhout I, van der Beek AJ, Burdorf A. Educational inequalities in the impact of chronic diseases on exit from paid employment among older workers: a 7-year prospective study in the Netherlands. Occup Environ Med. 2019;76(10):718-25.

[23] Vooijs IM. Supporting work participation of people with a chronic disease [PhD thesis]. Amsterdam, UvA; 2018.

[24] de Boer AG, Geuskens GA, Bültmann U, Boot CR, Wind H, Koppes LL, et al. Employment status transitions in employees with and without chronic disease in the Netherlands. Int J Public Health. 2018;63(6):713-22.

[25] Nivel. Workers with a chronic illness or disability rate their work with a score of 7.4 [internet]. Utrecht, Nivel; 2017. https://nivel.nl/sites/default/files/bestanden/factsheet_arbeid _tevredenheid_van_mensen_met_chronische_ziekte.pdf. Accessed May 192020.

[26] Van Rijn RM, Robroek SJ, Brouwer S, Burdorf A. Influence of poor health on exit from paid employment: a systematic review. Occup Environ Med. 2014;71(4):295-301.

[27] Schuring M, Robroek SJ, Otten FW, Arts CH, Burdorf A. The effect of ill health and socioeconomic status on labor force exit and re-employment: a prospective study with ten years follow-up in the Netherlands. Scand J Work Env Hea. 2013:134-43.

[28] Robroek SJ, Schuring M, Croezen S, Stattin M, Burdorf A. Poor health, unhealthy behaviors, and unfavorable work characteristics influence pathways of exit from paid employment among older workers in Europe: a four year follow-up study. Scand J Work Env Hea. 2013;125-33.

[29] Shultz KS, Wang M. The influence of specific physical health conditions on retirement decisions. Int J Aging Hum Dev. 2007;65(2):149-61.

[30] Laires PA, Serrano-Alarcón M, Canhão H, Perelman J. Multimorbidity and intention to retire: a cross-sectional study on 14 European countries. Int J Public Health. 2020;65(2): 187-95.

[31] Pietiläinen O, Laaksonen M, Rahkonen O, Lahelma E. Self-rated health as a predictor of disability retirement-the contribution of ill-health and working conditions. PloS One. 2011;6(9):e25004.

[32] Karpansalo M, Manninen P, Kauhanen J, Lakka TA, Salonen JT. Perceived health as a predictor of early retirement. Scand J Work Env Hea. 2004;30(4):287-92.

[33] Weijman I. Diabetes at work. Fatigue in relation to job characteristics, diabetes symptoms and self-management $[\mathrm{PhD}$ thesis]. Utrecht, Utrecht University; 2005.
[34] van Houtum L. Self-management and support needs of chronically ill people [PhD thesis]. Utrecht, Nivel; 2016.

[35] Baanders AN, Rijken PM, Peters L. Labour participation of the chronically ill: a profile sketch. Eur J Public Health. 2002;12(2):124-30.

[36] Kant I, Bültmann U, Schröer K, Beurskens A, Van Amelsvoort L, Swaen G. An epidemiological approach to study fatigue in the working population: the Maastricht Cohort Study. Occup Environ Med. 2003;60(suppl 1): i32-i9.

[37] Mohren D, Jansen N, van Amelsvoort L, Kant I. An epidemiological approach of fatigue and work: experiences from the Maastricht Cohort Study. Program Epidemiology of Work and Health Maastricht University, Maastricht; 2007.

[38] Peters V, De Rijk A, Engels J, Heerkens Y, Nijhuis F. A new typology of work schedules: Evidence from a crosssectional study among nurses working in residential elder care. Work. 2016;54(1):21-33.

[39] Kessler RC, et al. The world health organization health and work performance questionnaire (HPQ). J Occup Environ Med. 2003;45(2):156-74.

[40] Nivel. Increase in chronic diseases and multimorbidity: Aging population explains only part of the increase subsequent [internet]. Utrecht, Nivel; 2017. https://www.nivel. $\mathrm{nl} / \mathrm{nl} /$ publicatie/toename-chronische-ziekten-en-multimorbiditeit-veroudering-van-de-bevolking-verklaart. Accessed May 192020.

[41] O'halloran J, Miller GC, Britt H. Defining chronic conditions for primary care with ICPC-2. Fam Pract. 2004;21(4):381-6.

[42] Sociaal-Economische Raad. Work: important for everyone: An advice about working with a chronic illness [internet]. Den Haag, Sociaal-Economische Raad; 2016. https://www. ser.nl/-/media/ser/downloads/adviezen/2016/werken-chronische-ziekte.pdf. Accessed May 192020.

[43] Aaronson NK, et al. Translation, validation, and norming of the Dutch language version of the SF-36 Health Survey in community and chronic disease populations. J Clin Epidemiol. 1998;51(11):1055-68.

[44] Ware JE, Sherbourne C. The MOS 36-item short-form health survey (SF-36): I. Conceptual framework and item selection. Med Care. 1992;30(6):473-83.

[45] Dalstra JA, et al. Trends in socioeconomic health inequalities in the Netherlands, 1981-1999. J Epidemiol Commun H. 2002;56(12):927-34.

[46] Harkonmäki K, Rahkonen O, Martikainen P, Silventoinen K, Lahelma E. Associations of SF-36 mental health functioning and work and family related factors with intentions to retire early among employees. Occup Environ Med. 2006;63(8):558-63.

[47] Stynen D, Jansen NW, Kant I. The impact of work-related and personal resources on older workers' fatigue, work enjoyment and retirement intentions over time. Ergon. 2017;60(12):1692-707.

[48] Sewdas R, Thorsen SV, Boot CR, Bjørner JB, Van der Beek AJ. Determinants of voluntary early retirement for older workers with and without chronic diseases: A Danish prospective study. Scand J Public Heal. 2019;48(2): 190-9.

[49] Gründemann RWM, Smulders PWG, De Winter CR. Manual, questionnaire on work and health. Lisse: Swets \& Zeitlinger; 1993. 
[50] Van Veldhoven M, Meijman T. The measurement of psychosocial job demands with a questionnaire (VBBA). Amsterdam: NIA; 1994.

[51] Van Veldhoven M, Broersen S. Measurement quality and validity of the "need for recovery scale". J Occup Environ Med. 2003;60(suppl 1):i3-i9.

[52] Nilsson K. Why work beyond 65? Discourse on the decision to continue working or retire early. Nord J Work Life Stud. 2012;2(3):7-28.
[53] Rassen JA, Bartels DB, Schneeweiss S, Patrick AR, Murk W. Measuring prevalence and incidence of chronic conditions in claims and electronic health record databases. Clin Epidemiol. 2019;11:1. 